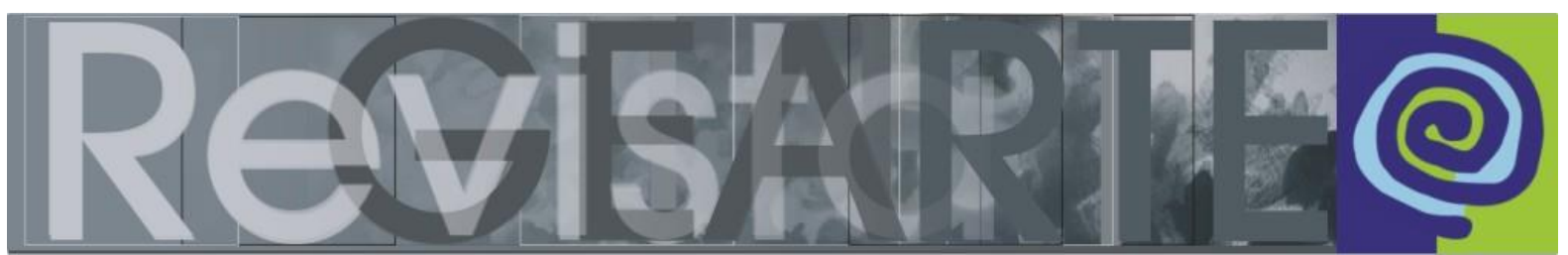

ISSN 2357-9854 | e-ISSN 2596-3198 (online)

\title{
Olhares em dobra: relações entre arte, ecologia e saúde
}

\author{
Cláudio Tarouco de Azevedo \\ (Universidade Federal do Rio Grande - FURG, Rio Grande/RS, Brasil \\ Universidade Federal de Pelotas — UFPel, Pelotas/RS, Brasil)
}

\begin{abstract}
RESUMO - Olhares em dobra: relações entre arte, ecologia e saúde - O projeto de pesquisa "A produção de subjetividade em Félix Guattari: experiências com arte, ecologia e saúde" acolhe pesquisadores em níveis de mestrado e iniciação científica, além de configurar um território cartográfico de incursões sob minhas próprias implicações enquanto professor/artista/orientador. Nesse sentido, este ensaio visual é resultado de uma investigação em meus próprios arquivos fotográficos. O caminho que me leva a esses arquivos se engendra no exercício de orientações junto ao Grupo de Pesquisa Arte, Ecologia e Saúde - GPAES/UFPel, porque é nessa prática que, por vezes, reconheço no outro as minhas inquietações e lembranças. Na tessitura orgânica da orientação, encontro vasão para prospectar em minhas fotografias um fio condutor que me desvele, embora parcialmente. Essa dobra sobre si revela a importância de olhar-se por meio das próprias produções. Assim, as imagens aqui compartilhadas pretendem promover multiplicidades a partir das relações entre arte, ecologia e saúde.
\end{abstract}

PALAVRAS-CHAVE

Fotografia. Ecologia. Multiplicidade.

RESUMEN - Miradas plegadas: relaciones entre arte, ecología y salud - El proyecto de investigación "La producción de subjetividad en Félix Guattari: experiencias con arte, ecología y salud" acoge investigadores en niveles de maestría e iniciación científica, además de configurar un territorio cartográfico de incursiones bajo mis propias implicaciones como profesor/artista/orientador. En este sentido, este ensayo visual es el resultado de una investigación en mis propios archivos fotográficos. El camino que me lleva a estos archivos se engendra en el ejercicio de orientaciones junto al Grupo de Investigación Arte, Ecología y Salud - GPAES/UFPel, porque es en esta práctica que, a veces, reconozco en el otro las mis inquietudes y recuerdos. En la tesitura orgánica de la orientación, encuentro salida para prospectar en mis fotografías un hilo conductor que me desvele, aunque parcialmente. Este pliegue sobre sí revela la importancia de mirarse por medio de las propias producciones. Así, las imágenes aquí compartidas pretenden promover multiplicidades a partir de las relaciones entre arte, ecología y salud.

PALABRAS CLAVE

Fotografía. Ecología. Multiplicidad.

ABSTRACT - Folded looks: relations between art, ecology and health - The research project "The production of subjectivity in Félix Guattari: experiences with art, ecology and health" welcomes researchers at master's and scientific initiation levels, in addition to setting up a territory cartographic of incursions under my own implications as a teacher / artist / advisor. In that sense, this visual essay is the result of an investigation into my own photographic archives. The path that takes me to these archives is engendered in the exercise of orientations with the Research Group Art, Ecology and Health - GPAES / UFPel, because it is in this practice that, sometimes, I recognize in my other concerns and memories. In the organic fabric of the orientation, I find space to explore in my photographs a guiding thread that reveals me, although partially. This fold over itself reveals the importance of looking at oneself through one's own productions. Thus, the images shared here are intended to promote multiplicity based on the relationship between art, ecology and health.

\section{KEYWORDS}

Photography. Ecology. Multiplicity. 

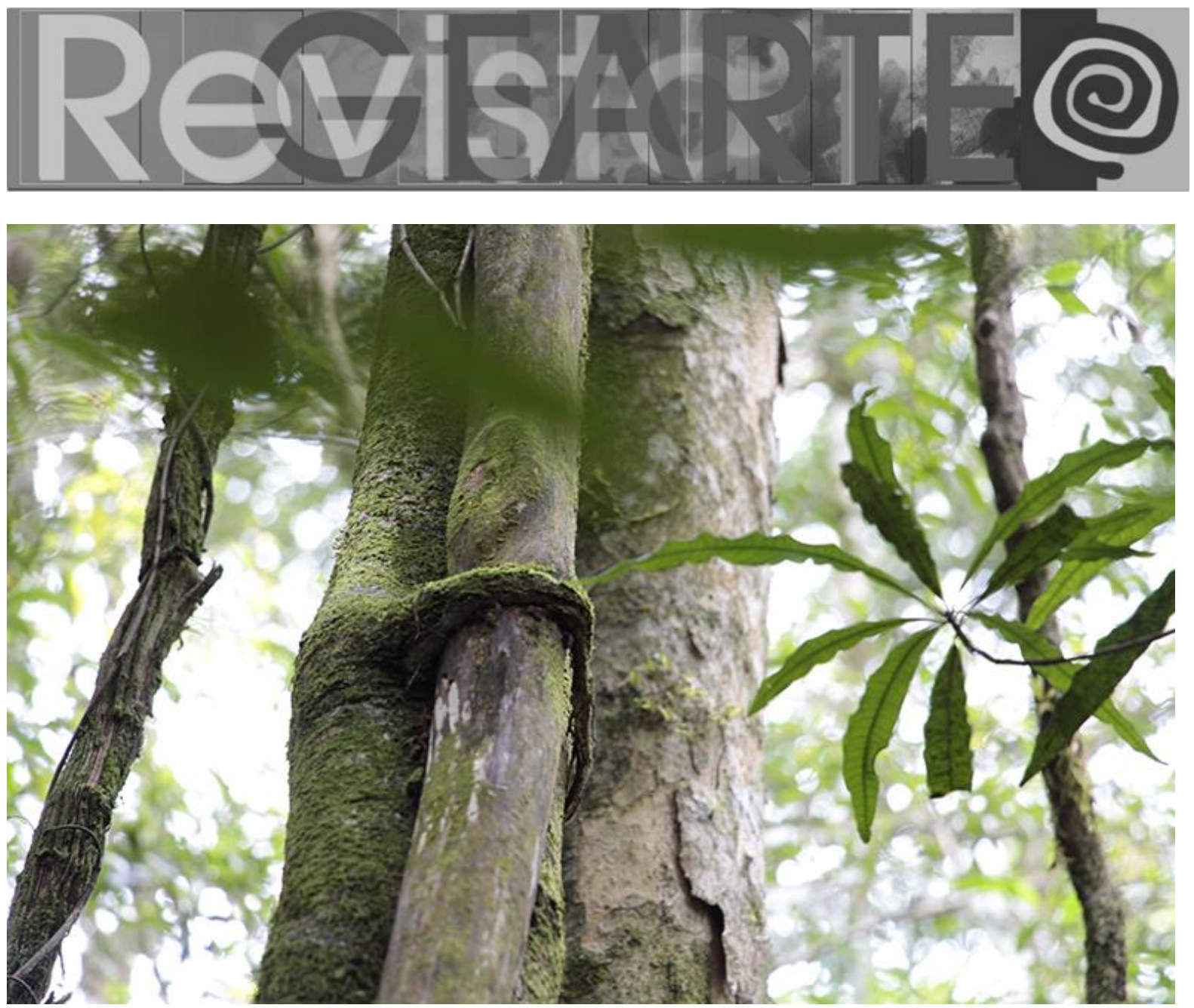

Há-braços, 2018.

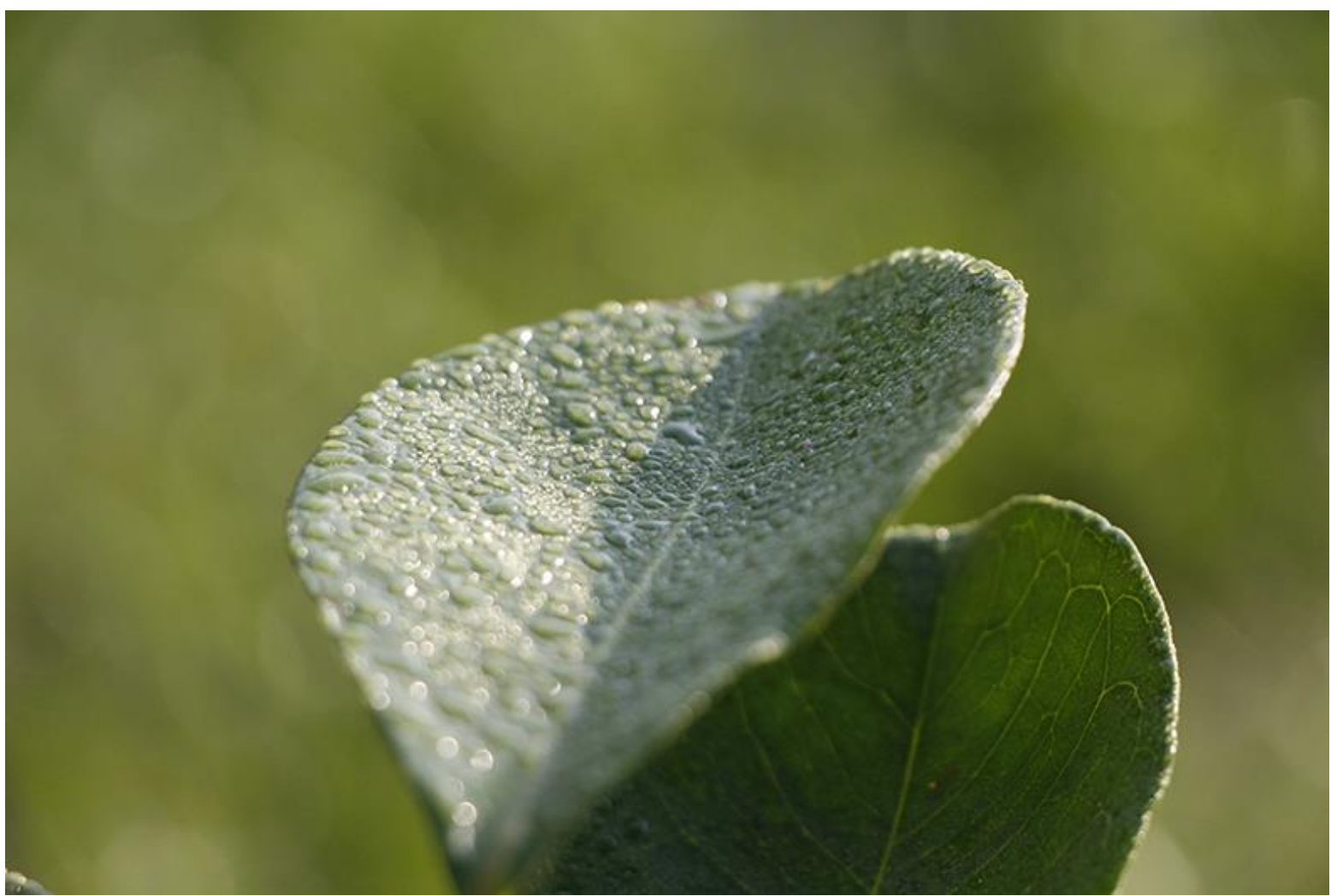

Água, 2018.

AZEVEDO, Cláudio Tarouco de. Olhares em dobra: relações entre arte, ecologia e saúde. Revista GEARTE, Porto Alegre, v. 7, n. 1, p. 244-248, jan./abr. 2020. 

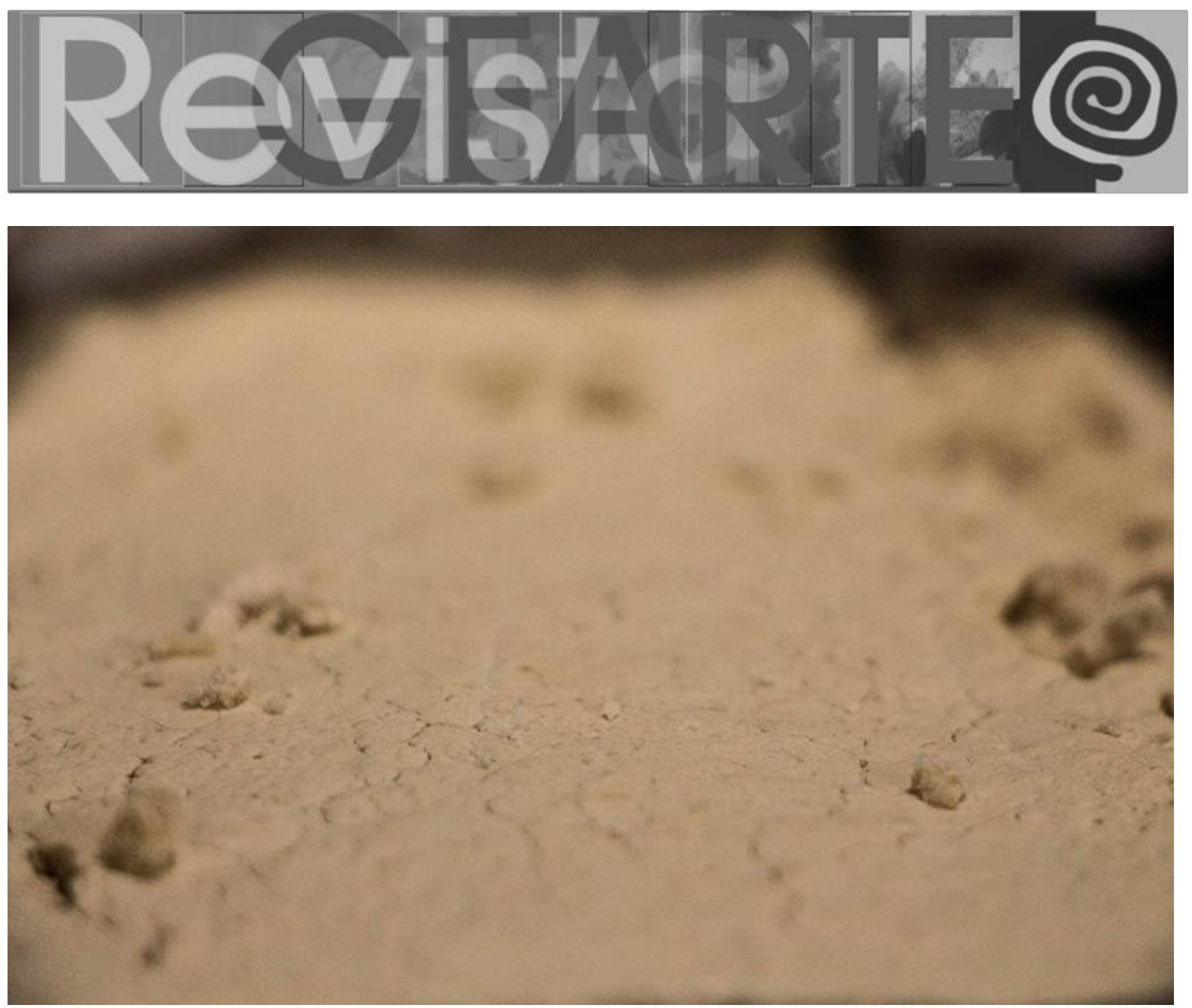

Seca, 2019.

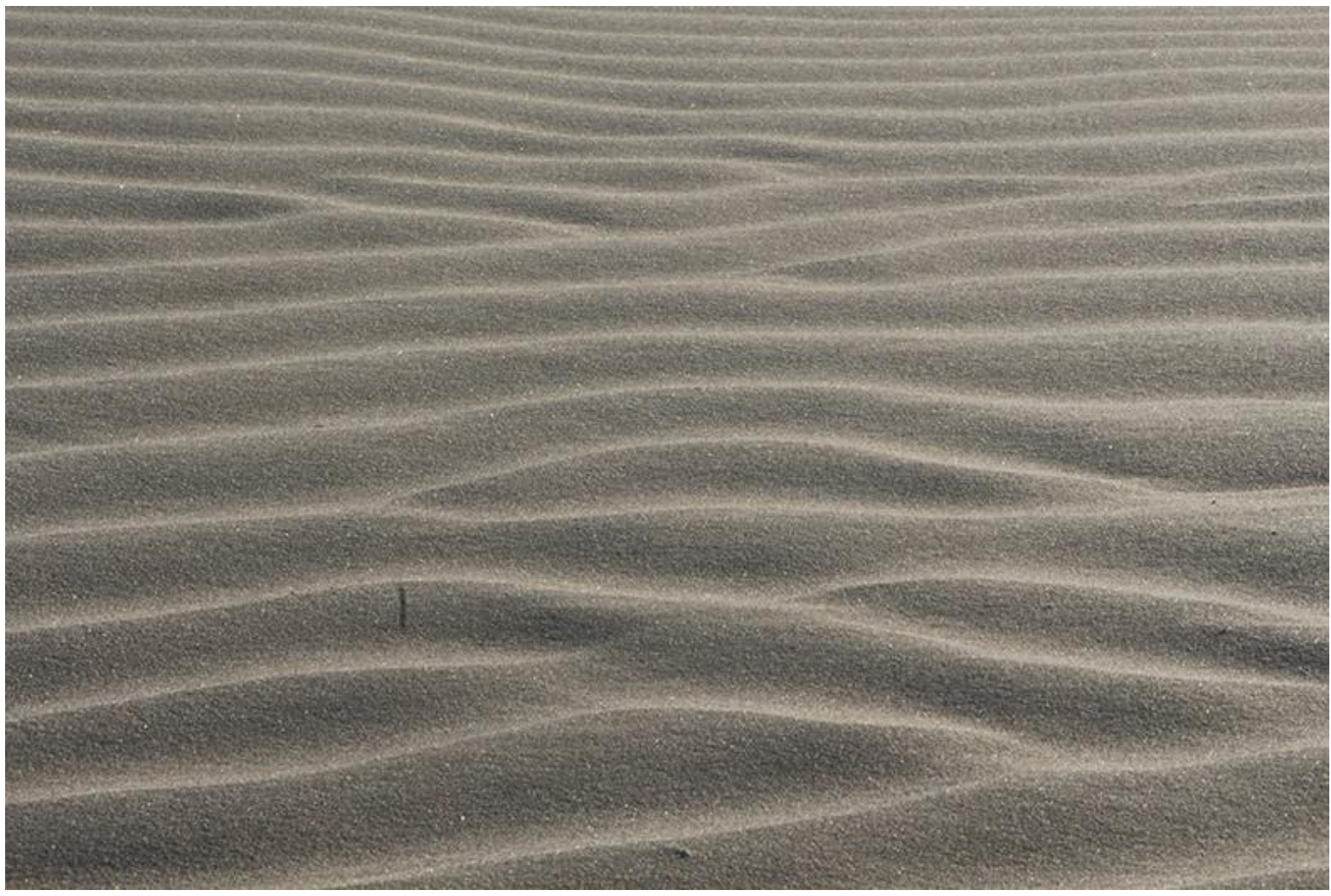

Ondas, 2018.

AZEVEDO, Cláudio Tarouco de. Olhares em dobra: relações entre arte, ecologia e saúde. Revista GEARTE, Porto Alegre, v. 7, n. 1, p. 244-248, jan./abr. 2020

Disponível em: http://seer.ufrgs.br/gearte 

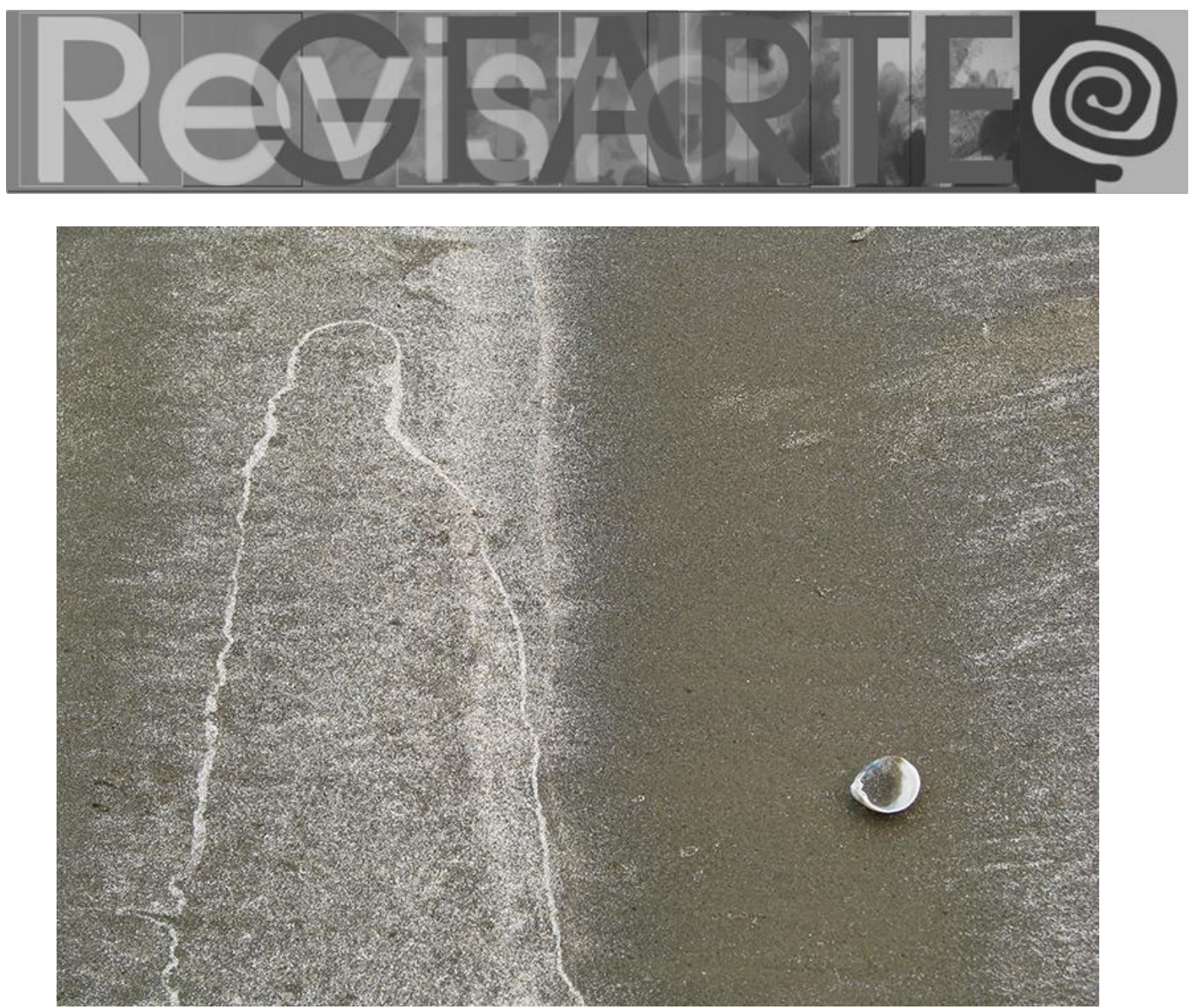

Vestígios, 2008.

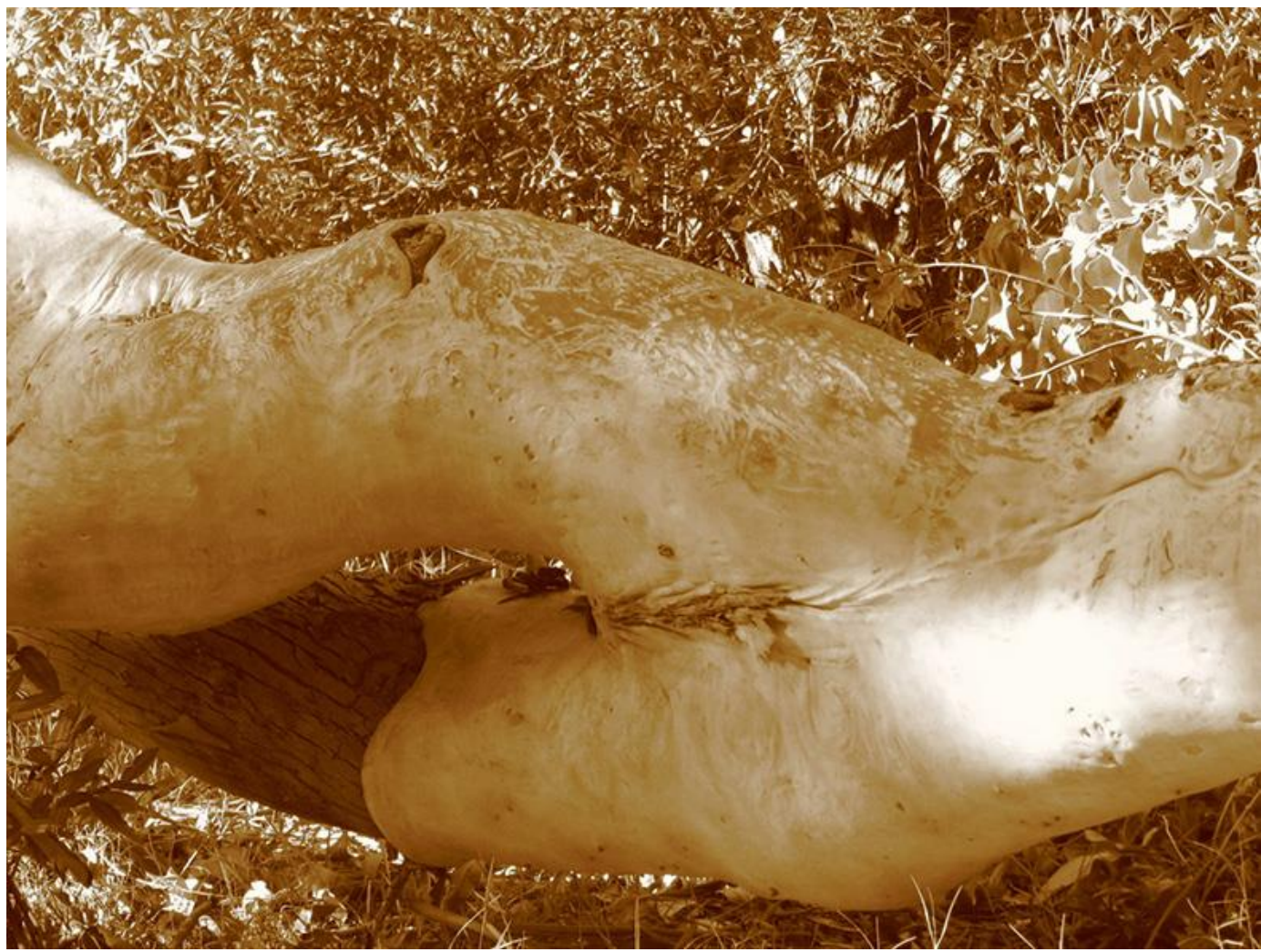

Corpo, 2008.

AZEVEDO, Cláudio Tarouco de. Olhares em dobra: relações entre arte, ecologia e saúde. Revista GEARTE, Porto Alegre, v. 7, n. 1, p. 244-248, jan./abr. 2020.

Disponível em: http://seer.ufrgs.br/gearte 


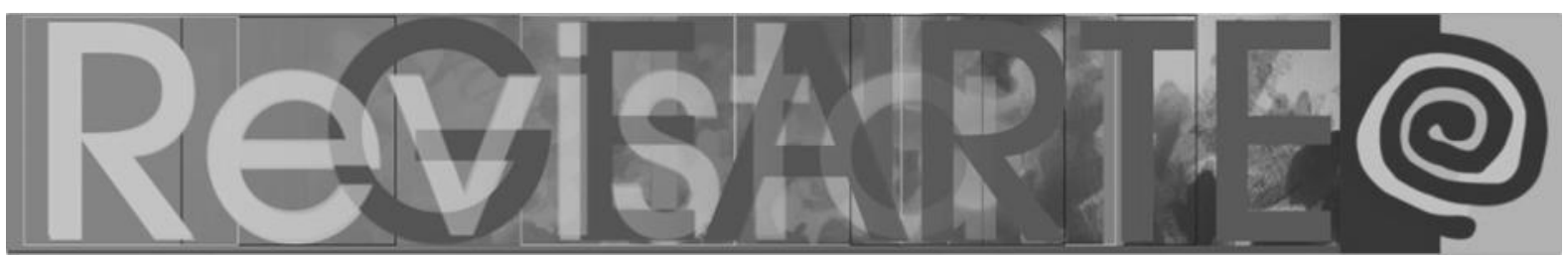

\section{Cláudio Tarouco de Azevedo}

Professor Adjunto do Instituto de Letras e Artes - ILA da Universidade Federal do Rio Grande FURG/RS. Membro do Grupo de Pesquisa Arte, Ecologia e Saúde - (GPAES/CNPq), compõe o corpo docente do Programa de Pós-Graduação em Artes Visuais - PPGAV da Universidade Federal de Pelotas (UFPel). Graduado em Artes Visuais Licenciatura pela FURG. Mestre e Doutor em Educação Ambiental (FURG) e Pós-Doutor em Artes Visuais pela UFPel. Possui experiência na área de Artes Visuais e Educação, com ênfase em Audiovisual, Fotografia e Educação Ambiental. Atuando principalmente nos seguintes temas: arte e ecologia, arte e saúde mental, ecosofia e Biorrizoma. Participa regularmente de exposições no Brasil e no exterior apresentando sua produção em poéticas visuais.

ORCID: https://orcid.org/0000-0002-7982-5878

E-mail: claudiohifi@yahoo.com.br

Currículo: http://lattes.cnpq.br/8041917371066975

Recebido em 24 de março de 2019

Aceito em 9 de setembro de 2019 